\title{
NOTA
}

\section{ACIDEZ POTENCIAL ESTIMADA PELO MÉTODO DO pH SMP EM SOLOS DA REGIÃO DO VALE DO JEQUITINHONHA NO ESTADO DE MINAS GERAIS ${ }^{(1)}$}

\author{
Enilson de Barros Silva ${ }^{(2)}$, Hesmael Antonio Orlandi Costa ${ }^{(3)}$ \& Múcio \\ Magno de Melo Farnezi ${ }^{(3)}$
}

\begin{abstract}
RESUMO
A acidez potencial tem grande importância pelo seu uso na determinação da necessidade de calagem pelo método da saturação de bases. O objetivo deste trabalho foi definir uma equação de regressão que estime o teor de $\mathrm{H}+\mathrm{Al}$ a partir do pH SMP medido na suspensão solo-solução SMP, associada à determinção do pH em água, para solos da Região do Vale do Jequitinhonha. As análises dos teores de $\mathrm{H}+\mathrm{Al}$, extraídos por acetato de cálcio $0,5 \mathrm{~mol} \mathrm{~L}^{-1}$ a $\mathrm{pH} 7,0$, e dos valores de pH SMP foram realizadas no laboratório de fertilidade do solo da UFVJM em 50 amostras de solos, com valores de $\mathrm{pH}$ em água variando de 4,0 a 7,6, teores de carbono orgânico de 1 a $29 \mathrm{~g} \mathrm{~kg}^{-1}$ e os de argila de 100 a $810 \mathrm{~g} \mathrm{~kg}^{-1}$. A acidez potencial, expressa em $\mathrm{cmol}_{\mathrm{c}} \mathrm{dm}^{-3}$, pode ser estimada pelo uso do pH SMP, por meio da equação: $\operatorname{Ln}(\mathrm{H}+\mathrm{Al})=8,26-1,124312$ pH $\operatorname{SMP}\left(\mathrm{R}^{2}=0,97\right)$.
\end{abstract}

Termos de indexação: pH do solo, necessidade de calagem, solução-tampão, H + Al.

SUMMARY: POTENTIAL ACIDITY ESTIMATED BY $p H$ SMP METHOD IN SOILS OF THE JEQUITINHONHA VALLEY, MINAS GERAIS STATE, BRAZIL

The potential acidity is important because it is used in the determination of base saturation and the estimation of lime requirement. The objective of this study was to establish a regression equation to estimate the potential acidity with the SMP-pH measured

\footnotetext{
(1) Recebido para publicação em dezembro de 2004 e aprovado em maio de 2006.

(2) Professor Adjunto do Departamento de Agronomia da Universidade Federal dos Vales do Jequitinhonha e Mucuri - UFVJM. Caixa Postal 38, CEP 39100-000 Diamantina (MG). E-mail: ebsilva@fafeid.edu.br.

${ }^{(3)}$ Aluno do Curso de Mestrado em Produção Vegetal, UFVJM. Caixa Postal 38, CEP 39100-000 Diamantina (MG).
} 
in water under agitation of the SMP equilibrium solution with soil samples from the Jequitinhonha Valley, Minas Gerais State, Brazil. The H + Al concentration measured by $0.5 \mathrm{~mol} \mathrm{~L}^{-1}$ calcium acetate $\mathrm{pH} 7.0$ and SMP pH were determined in 50 soil samples at the soil fertility laboratory of the UFVJM (Federal University of the Jequitinhonha and Mucuri Valleys). Their $\mathrm{pH}$ in water ranged from 4.0 to 7.6, organic carbon concentration varied from 1 to $29 \mathrm{~g} \mathrm{~kg}^{-1}$ and the clay content ranged from 100 to $810 \mathrm{~g} \mathrm{~kg}^{-1}$. The potential acidity, expressed in $\mathrm{cmol}_{c} \mathrm{dm}^{-3}$, can be estimated by measuring the SMP $\mathrm{pH}$ using the equation: $\operatorname{Ln}(H+A l)=8.26-1.124312 p H S M P\left(R^{2}=0.97\right)$

Index terms: soil pH, lime requirement, buffer solution, $H+A l$.

\section{INTRODUÇÃO}

Na recomendação de calagem no Estado de Minas Gerais; são utilizados os métodos da neutralização do $\mathrm{Al}$ trocável e elevação dos teores de $\mathrm{Ca}$ e de $\mathrm{Mg}$ trocáveis e o da elevação da saturação por bases (Alvarez V. \& Ribeiro, 1999). Este último considera a capacidade de troca cátions (CTC) a pH 7,0 dos solos, cujo cálculo leva em conta, dentre outras propriedades, a acidez potencial.

A acidez potencial é constituída pela somatória do $\mathrm{H}+\mathrm{Al}$ do solo, extraídos com soluções de sais tamponadas ou misturas de sais neutros com soluçãotampão (Peech, 1965). Nessa análise, as soluções mais empregadas são o cloreto de bário tamponado com trietanolamina a $\mathrm{pH} 8,2$, o acetato de cálcio $0,5 \mathrm{~mol} \mathrm{~L}^{-1}$ a pH 7,0 e a solução-tampão SMP (Raij, 1991).

No Brasil, o método de determinação da acidez potencial com a solução de acetato de cálcio $0,5 \mathrm{~mol} \mathrm{~L}^{-1}$ a pH 7,0 é considerado como padrão (Raij et al., 1987). A solução de acetato de cálcio, por ter o $\mathrm{pH}$ tamponado a 7,0, pode extrair grande parte da acidez potencial (Vettorri, 1969). Esse método, entretanto, tem apresentado algumas limitações, tais como: consumo de grande quantidade de reagente por amostra (Moreira et al., 2004); difícil visualização do ponto de viragem do indicador (fenolftaleína) (Pereira et al., 1998); custo e tempo operacional elevados, por envolver as etapas de extração e determinação titulométrica do $\mathrm{H}+\mathrm{Al}$ (Escosteguy \& Bissani, 1999), e subestimação dos teores de $\mathrm{H}+\mathrm{Al}$ de solos de $\mathrm{pH}$ mais alto (acima de 6,0), o que se deve ao tamponamento deficiente da solução em solos com $\mathrm{pH}$ em água em torno de pH 7,0 (Raij, 1991).

Segundo Raij et al. (1987) e Ciprandi (1993), a acidez potencial pode ser estimada pelo uso do $\mathrm{pH}$ SMP, o qual apresenta boa correlação com o teor de $\mathrm{H}+\mathrm{Al}$ extraído com acetato de cálcio. O pH SMP corresponde ao valor do $\mathrm{pH}$ de equilíbrio obtido na suspensão entre o solo e a solução-tampão SMP, que foi utilizado, inicialmente, como método rápido de determinação da necessidade de calagem (Shoemaker et al., 1961). Considerando a facilidade e a eficiência apresentada na estimativa da acidez potencial, esse método tem sido utilizado por vários laboratórios brasileiros em substituição ao método da solução de acetato de cálcio.
A determinação do pH SMP é feita com a adição da solução-tampão após determinação do $\mathrm{pH}$ do solo em $\mathrm{CaCl}_{2}$ 0,01 mol L-1, sendo a leitura feita no sobrenadante, de modo que o bulbo do eletrodo toque ligeiramente o solo sedimentado no fundo do frasco (Corrêa et al., 1985; Quaggio et al., 1985; Sousa et al., 1989; Maeda et al., 1997; Pereira et al., 1998; Gama et al., 2002; Sambatti et al., 2003 e Moreira et al., 2004). Outros autores associaram o uso da solução SMP à determinação do $\mathrm{pH}$ do solo em água determinando-se o pH SMP no sobrenadante (Nascimento, 2000; Silva et al., 2000, Silva et al., 2002 e Moreira et al., 2004) ou na suspensão solo-solução (Pavan et al., 1996; Escostegury \& Bissani, 1999, Silva, 1999 e Kamiski et al., 2002).

As diferenças na determinação do pH SMP e as influências das características dos solos conferem ampla variação nas equações. Em razão disso, as equações são de uso restrito para as condições de solo e procedimentos operacionais que foram estabelecidas.

O objetivo deste trabalho foi definir uma equação de regressão que estime a acidez potencial $(\mathrm{H}+\mathrm{Al}) \mathrm{a}$ partir do $\mathrm{pH}$ SMP associado à determinção do $\mathrm{pH}$ em água, para solos da Região do Vale do Jequitinhonha, Estado de Minas Gerais.

\section{MATERIAL E MÉTODOS}

Este trabalho foi realizado no laboratório de fertilidade do solo do Departamento de Agronomia do Instituto de Ciências Agrárias da Universidade Federal dos Vales do Jequitinhonha e Mucuri (UFVJM) em Diamantina, MG. Foram selecionadas 50 amostras de solo provenientes de vários municípios da Região do Vale do Jequitinhonha, Estado de Minas Gerais, com variação na classificação em nível de subordem, segundo Embrapa (1999), em valores de pH em água, pH SMP, Al trocável, acidez potencial, C orgânico e no teor de argila (Quadro 1).

$\mathrm{Na}$ determinação da acidez potencial $(\mathrm{H}+\mathrm{Al})$, foram utilizados $5,0 \mathrm{~cm}$ de terra fina seca ao ar e $75 \mathrm{~mL}$ da solução de $\mathrm{Ca}\left(\mathrm{CH}_{3} \mathrm{COO}\right)_{2} \cdot \mathrm{H}_{2} \mathrm{O} 0,5 \mathrm{~mol} \mathrm{~L}^{-1}$ a pH 7,0, em erlenmeyer de $125 \mathrm{~mL}$. Após agitação por 15 min e repouso de $16 \mathrm{~h}$, retirou-se uma alíquota 
Quadro 1. Classificação dos solos selecionados e valores de pH em água, pH SMP, alumínio trocável (Al $\left.{ }^{3+}\right)$, acidez potencial (H + Al), carbono orgânico (C.O.) e argila das amostras utilizadas

\begin{tabular}{|c|c|c|c|c|c|c|}
\hline Classificação do solo ${ }^{(1)}$ & pH água & pH SMP & $\mathrm{Al}^{3+}$ & $\mathbf{H}+\mathbf{A l}$ & C.O. & Argila \\
\hline & & & \multicolumn{2}{|c|}{$-\mathrm{cmol}_{\mathrm{c}} \mathrm{dm}^{-3}-$} & \multicolumn{2}{|c|}{$\mathrm{g} \mathrm{kg}^{-1}$} \\
\hline Argilossolo Acinzentado & 5,0 & 6,1 & 3,6 & 4,2 & 1 & 610 \\
\hline Argilossolo Vermelho & 5,8 & 6,3 & 0,1 & 3,3 & 9 & 510 \\
\hline Argilossolo Vermelho & 5,8 & 6,3 & 0,3 & 3,3 & 8 & 110 \\
\hline Argilossolo Vermelho-Amarelo & 5,1 & 5,9 & 0,3 & 5,2 & 6 & 360 \\
\hline Argilossolo Vermelho-Amarelo & 7,0 & 7,1 & 0,1 & 1,3 & 8 & 200 \\
\hline Argilossolo Vermelho-Amarelo & 6,0 & 6,5 & 0,3 & 2,5 & 3 & 160 \\
\hline Argilossolo Vermelho-Amarelo & 5,0 & 6,4 & 0,3 & 3,2 & 2 & 160 \\
\hline Argilossolo Vermelho-Amarelo & 4,2 & 5,2 & 1,4 & 8,7 & 12 & 310 \\
\hline Argilossolo Vermelho-Amarelo & 5,1 & 5,2 & 1,1 & 11,4 & 17 & 160 \\
\hline Argilossolo Vermelho-Amarelo & 4,2 & 5,4 & 3,5 & 10,3 & 29 & 110 \\
\hline Argilossolo Vermelho-Amarelo & 5,8 & 5,3 & 0,7 & 14,0 & 22 & 160 \\
\hline Argilossolo Vermelho-Amarelo & 4,8 & 4,7 & 2,5 & 14,7 & 19 & 260 \\
\hline Argilossolo Vermelho-Amarelo & 5,1 & 5,2 & 2,0 & 11,4 & 16 & 460 \\
\hline Argilossolo Vermelho-Amarelo & 5,4 & 5,2 & 0,8 & 11,4 & 20 & 410 \\
\hline Cambissolo & 4,8 & 6,0 & 0,5 & 4,7 & 9 & 560 \\
\hline Latossolo Vermelho & 7,6 & 7,0 & 0,1 & 1,5 & 19 & 460 \\
\hline Latossolo Vermelho & 6,0 & 6,3 & 0,7 & 3,8 & 14 & 460 \\
\hline Latossolo Vermelho & 5,0 & 5,4 & 0,6 & 8,6 & 18 & 460 \\
\hline Latossolo Vermelho & 6,4 & 6,4 & 0,3 & 3,2 & 14 & 610 \\
\hline Latossolo Vermelho & 5,9 & 5,9 & 0,4 & 5,2 & 24 & 610 \\
\hline Latossolo Vermelho & 5,0 & 5,6 & 0,5 & 7,3 & 22 & 510 \\
\hline Latossolo Vermelho & 4,6 & 5,1 & 0,1 & 11,4 & 16 & 710 \\
\hline Latossolo Vermelho & 4,9 & 5,1 & 1,6 & 12,0 & 21 & 610 \\
\hline Latossolo Vermelho & 5,5 & 5,3 & 1,5 & 13,2 & 24 & 610 \\
\hline Latossolo Vermelho & 5,0 & 4,9 & 2,3 & 14,5 & 23 & 360 \\
\hline Latossolo Vermelho & 4,7 & 6,3 & 1,7 & 3,3 & 6 & 760 \\
\hline Latossolo Vermelho & 6,4 & 6,5 & 0,1 & 2,7 & 12 & 210 \\
\hline Latossolo Vermelho & 5,2 & 5,6 & 0,4 & 7,3 & 12 & 510 \\
\hline Latossolo Vermelho & 4,7 & 5,2 & 1,3 & 11,4 & 10 & 460 \\
\hline Latossolo Vermelho & 5,6 & 5,8 & 0,1 & 5,8 & 27 & 810 \\
\hline Latossolo Vermelho-Amarelo & 7,4 & 7,1 & 0,1 & 1,3 & 12 & 360 \\
\hline Latossolo Vermelho-Amarelo & 6,5 & 6,8 & 0,1 & 1,7 & 9 & 610 \\
\hline Latossolo Vermelho-Amarelo & 4,6 & 5,0 & 1,9 & 9,2 & 17 & 410 \\
\hline Latossolo Vermelho-Amarelo & 4,0 & 6,2 & 2,2 & 3,7 & 5 & 710 \\
\hline Latossolo Vermelho-Amarelo & 5,2 & 5,8 & 0,5 & 5,8 & 7 & 660 \\
\hline Latossolo Vermelho-Amarelo & 5,3 & 6,1 & 0,3 & 4,2 & 7 & 360 \\
\hline Latossolo Vermelho-Amarelo & 5,4 & 6,5 & 0,1 & 2,7 & 12 & 760 \\
\hline Neossolo Quartzarênico & 5,7 & 7,4 & 0,1 & 0,9 & 7 & 60 \\
\hline Neossolo Quartzarênico & 6,6 & 6,8 & 0,5 & 1,7 & 8 & 50 \\
\hline Neossolo Quartzarênico & 7,0 & 6,6 & 0,1 & 2,2 & 6 & 80 \\
\hline Neossolo Quartzarênico & 6,6 & 6,7 & 0,1 & 2,0 & 5 & 90 \\
\hline Neossolo Quartzarênico & 7,0 & 6,6 & 0,1 & 2,1 & 3 & 70 \\
\hline Neossolo Quartzarênico & 4,7 & 6,8 & 1,2 & 1,9 & 6 & 90 \\
\hline Neossolo Quartzarênico & 5,4 & 6,3 & 0,1 & 3,9 & 25 & 80 \\
\hline Neossolo Quartzarênico & 5,6 & 6,2 & 0,1 & 3,7 & 6 & 50 \\
\hline Neossolo Quartzarênico & 4,6 & 5,1 & 1,3 & 12,7 & 15 & 60 \\
\hline Nitossolo Vermelho & 6,3 & 6,5 & 0,1 & 2,7 & 13 & 510 \\
\hline Nitossolo Vermelho & 6,3 & 6,6 & 0,1 & 2,4 & 12 & 610 \\
\hline Nitossolo Vermelho & 5,0 & 4,9 & 1,1 & 15,9 & 25 & 510 \\
\hline Nitossolo Vermelho & 4,8 & 5,2 & 0,6 & 11,4 & 16 & 460 \\
\hline
\end{tabular}

(1) Embrapa (1999). $\mathrm{pH}_{\text {água }}$ - relação solo-água 1:2,5; pH SMP - na suspensão solo-solução associada à determinação do $\mathrm{pH}$ em água; $\mathrm{Al}^{3+}$ - extrator KCl $1 \mathrm{~mol} \mathrm{~L}{ }^{-1}$ e dosagem titulométrica ácido-base; $\mathrm{H}+\mathrm{Al}$ - extrator acetato de cálcio $0,5 \mathrm{~mol} \mathrm{~L}{ }^{-1}$ e dosagem titulométrica ácido-base; C.O. - método Walkley \& Black; Argila - método da pipeta. 
de $25 \mathrm{~mL}$ do sobrenadante para determinar o teor de $\mathrm{H}+\mathrm{Al}$ por titulação com $\mathrm{NaOH} 0,025 \mathrm{~mol} \mathrm{~L}^{-1}$, utilizando fenolftaleína como solução indicadora (Embrapa, 1997).

Para o pH em água utilizou-se a relação solo:solução de 1:2,5, determinando-o na suspensão (Embrapa, 1997). Após a leitura do $\mathrm{pH}$ do solo, adicionaram-se 5,0 mL da solução-tampão SMP a $\mathrm{pH} 7,5$, agitando por 15 min a $220 \mathrm{rpm}$. Após repouso por $60 \mathrm{~min}$, procedeu-se à leitura do $\mathrm{pH}$ de equilíbrio na suspensão solo, após agitação. Desse molo, preservou-se a proporção solo:água:solução SMP de 10:25:5 adotada por Quaggio \& Raij (2001). As análises de $\mathrm{pH}$ SMP e de $\mathrm{H}+\mathrm{Al}$ em acetato de cálcio foram efetuadas em três repetições.

Utilizou-se os valores médios para ajustar a equação de regressão relacionando o pH SMP e o $\mathrm{H}+\mathrm{Al}$, com o uso de Software Table Curve. Escolheuse a equação de melhor ajuste de acordo com o maior coeficiente de determinação. Estimou-se o $\mathrm{H}+\mathrm{Al}$ para os 50 solos por meio dessa regressão e de 15 outras em uso no Brasil, sendo as estimativas comparadas pelo teste de Wilcoxon a 5 \% (Campos, 1983).

\section{RESULTADOS E DISCUSSÃO}

A equação exponencial foi a que melhor expressou a relação entre o $\mathrm{H}+\mathrm{Al}$ e o $\mathrm{pH} \mathrm{SMP}\left(\mathrm{R}^{2}=0,97\right)$ (Figura 1). Com essa equação estimou-se a acidez potencial a partir do $\mathrm{pH}$ SMP de 4,70 a 7,40 (Quadro 2), que é aplicável para solos da Região do Vale do Jequitinhonha do Estado de Minas Gerais. Cabe mencionar que, para solos com valores de $\mathrm{H}+\mathrm{Al}$ acima de $8 \mathrm{cmol}_{\mathrm{c}} \mathrm{dm}^{-3}$, ocorreu maior dispersão dos dados. Esta tendência pode ser explicada pela menor sensibilidade do método SMP quando se utiliza relações solo:água:solução SMP de 10:25:5. O reduzido volume de tampão é insuficiente para solos de maior tamponamento, sendo que nesse caso recomenda-se a relação 10:20:10 (Raij et al., 1979).

$\mathrm{O}$ atributo do solo que mais influiu na acidez potencial dos 50 solos do Vale do Jequitinhonha foi o teor de carbono orgânico, pela melhor correlação positiva (Figura 2). Isso se deve a importância do $\mathrm{H}$ associado às cargas negativas dependentes de $\mathrm{pH}$ dos colóides orgânicos, que se dá por ligações covalentes sendo, portanto, dissociável com a elevação do $\mathrm{pH}$ pela solução SMP a pH 7,5. A correlação não significativa com o teor de argila (Figura 2), decorre de sua variação qualitativa entre os solos.

A correlação positiva do $\mathrm{Al}$ trocável e $\mathrm{H}+\mathrm{Al}$ era esperada pelo fato de a acidez potencial $(\mathrm{H}+\mathrm{Al})$ referirse ao total de $\mathrm{H}$ em ligação covalente, mais o $\mathrm{Al}$, ou seja, a soma da acidez não-trocável e trocável. Da mesma forma, a correlação negativa com $\mathrm{pH}$ em água do solo deve-se à relação inversa entre $\mathrm{pH} \mathrm{e} \mathrm{Al}^{3+}$.

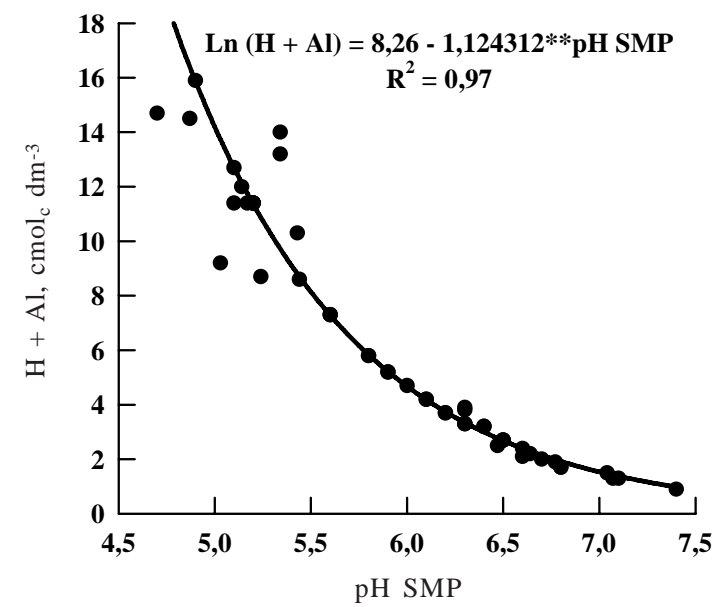

Figura 1. Relação entre acidez potencial $(\mathrm{H}+\mathrm{Al})$ extraídos com acetato de cálcio e $\mathrm{pH}$ SMP para solos da Região do Vale do Jequitinhonha. (** significativo a $1 \%$ pelo teste $t$ )

Quadro 2. Estimativa da acidez potencial a partir do pH SMP para solos da Região Vale do Jequitinhonha

\begin{tabular}{|c|c|c|c|}
\hline pH SMP & $\mathbf{H}+\mathbf{A l}$ & pH SMP & $\mathbf{H}+\mathbf{A l}$ \\
\hline & $\mathrm{cmol}_{\mathrm{c}} \mathrm{dm}^{-3}$ & & $\mathrm{cmol}_{\mathrm{c}} \mathrm{dm}^{-3}$ \\
\hline 4,70 & 19,60 & 6,10 & 4,06 \\
\hline 4,75 & 18,53 & 6,15 & 3,84 \\
\hline 4,8 & 17,52 & 6,20 & 3,63 \\
\hline 4,85 & 16,56 & 6,25 & 3,43 \\
\hline 4,9 & 15,66 & 6,30 & 3,24 \\
\hline 4,95 & 14,80 & 6,35 & 3,07 \\
\hline 5,00 & 13,99 & 6,40 & 2,90 \\
\hline 5,05 & 13,23 & 6,45 & 2,74 \\
\hline 5,10 & 12,50 & 6,50 & 2,59 \\
\hline 5,15 & 11,82 & 6,55 & 2,45 \\
\hline 5,20 & 11,17 & 6,60 & 2,32 \\
\hline 5,25 & 10,56 & 6,65 & 2,19 \\
\hline 5,30 & 9,99 & 6,70 & 2,07 \\
\hline 5,35 & 9,44 & 6,75 & 1,96 \\
\hline 5,40 & 8,92 & 6,80 & 1,85 \\
\hline 5,45 & 8,44 & 6,85 & 1,75 \\
\hline 5,50 & 7,97 & 6,90 & 1,65 \\
\hline 5,55 & 7,54 & 6,95 & 1,56 \\
\hline 5,60 & 7,13 & 7,00 & 1,48 \\
\hline 5,65 & 6,74 & 7,05 & 1,40 \\
\hline 5,70 & 6,37 & 7,10 & 1,32 \\
\hline 5,75 & 6,02 & 7,15 & 1,25 \\
\hline 5,80 & 5,69 & 7,20 & 1,18 \\
\hline 5,85 & 5,38 & 7,25 & 1,11 \\
\hline 5,90 & 5,09 & 7,30 & 1,05 \\
\hline 5,95 & 4,81 & 7,35 & 1,00 \\
\hline 6,00 & 4,55 & 7,40 & 0,94 \\
\hline 6,05 & 4,30 & & \\
\hline
\end{tabular}

A comparação da estimativa da acidez potencial das amostras de solo utilizadas com as equações ajustadas para diferentes Estados e regiões brasileiras encontra-se no quadro 3. A acidez potencial estimada 
por meio das regressões em que o $\mathrm{pH}$ SMP é medido no sobrenadante, em $\mathrm{CaCl}_{2} 0,01 \mathrm{~mol} \mathrm{~L}^{-1}$ (Sousa et al., 1989), bem como as estimadas pelas equações de Escosteguy \& Bissani (1999) e Kamiski et al. (2002), foram significativamente diferentes da estimada pela equação obtida neste estudo, o que já era esperado em decorrência das diferentes características dos solos, tais como: CTC, matéria orgânica, pH do solo, teor e tipo de argila, dentre outras.
A determinação do pH SMP em água, na suspensão após o equilíbrio, deve-se ao fato de o método apresentar baixo custo e ser de fácil realização na rotina de determinação do $\mathrm{pH}$ em água, o que também foi discutido por Moreira et al. (2004). Todavia, a determinação do $\mathrm{pH}$ em $\mathrm{CaCl}_{2}$ é aconselhável em solos submetidos ao uso intenso de corretivos e de fertilizantes. A determinação do pH SMP na suspensão é um procedimento de mais fácil execução pelo
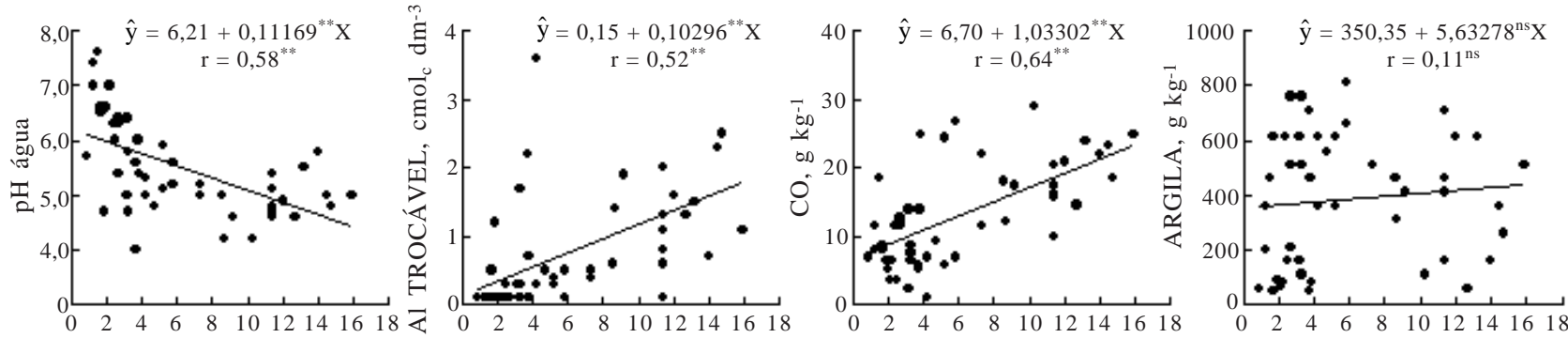

$\mathrm{H}+\mathrm{Al}, \mathrm{cmol}_{\mathrm{c}} \mathrm{dm}^{-3}$

Figura 2. Correlação linear simples entre pH em água, $\mathrm{Al}$ trocável $\left(\mathrm{Al}^{3+}\right)$, carbono orgânico (CO) e teor de argila e a acidez potencial $(\mathrm{H}+\mathrm{Al})$. (** significativo a $1 \%$ pelo teste de $\mathrm{t})$.

Quadro 3. Comparação dos valores de H + Al estimados a partir do pH SMP, por meio de equações ajustadas para diferentes Estados e regiões brasileiros

\begin{tabular}{|c|c|c|c|c|c|c|}
\hline \multirow{2}{*}{ Região ou Estado } & \multirow{2}{*}{ Referência ${ }^{(1)}$} & \multicolumn{3}{|c|}{$\mathrm{H}+\mathrm{Al}\left(\mathrm{cmol}_{\mathrm{c}} \mathrm{dm}^{-3}\right)$} & \multirow{2}{*}{$\underset{(\%)}{\text { Índice }}$} & \multirow{2}{*}{$\chi^{2}$} \\
\hline & & Máximo & Mínimo & Média & & \\
\hline \multicolumn{7}{|c|}{ Medição em $\mathrm{CaCl}_{2}$ sem agitação da solução SMP de equilíbrio } \\
\hline Minas Gerais & Corrêa et al. (1985) & 17,09 & 0,85 & 5,51 & 86 & 1,08 \\
\hline São Paulo & Quaggio et al. (1985) & 16,62 & 0,97 & 5,62 & 88 & 0,73 \\
\hline Cerrados & Sousa et al. (1989) & 14,87 & 0,83 & 4,96 & 78 & $1,62^{*}$ \\
\hline Mato Grosso Sul & Maeda et al. (1997) & 22,08 & 1,26 & 7,41 & 116 & 1,17 \\
\hline Rio de Janeiro & Pereira et al. (1998) & 19,17 & 1,22 & 6,65 & 104 & 0,70 \\
\hline Nordeste Paraense & Gama et al. (2002) & 13,18 & 2,15 & 6,21 & 97 & 0,92 \\
\hline Noroeste do Paraná & Sambatti et al. (2003) & 7,75 & 0,59 & 4,38 & 68 & 1,05 \\
\hline Amazonas & Moreira et al. (2004) & 12,14 & 1,78 & 7,26 & 114 & 1,00 \\
\hline \multicolumn{7}{|c|}{ Medição em água sem agitação da solução SMP de equilíbrio } \\
\hline Pernambuco & Nascimento et al. (2000) & 9,25 & 2,14 & 5,26 & 82 & 0,40 \\
\hline Semi-árido do Nordeste & Silva et al. (2000) & 19,90 & 0,78 & 6,76 & 106 & 0,17 \\
\hline Norte de Minas Gerais & Silva et al. (2002) & 14,16 & 0,96 & 5,00 & 78 & 1,22 \\
\hline Amazonas & Moreira et al. (2004) & 12,56 & 2,17 & 7,67 & 120 & 1,31 \\
\hline \multicolumn{7}{|c|}{ Medição em água com agitação da solução SMP de equilíbrio } \\
\hline Paraná & Pavan et al. (1996) & 13,08 & 1,75 & 5,78 & 90 & 0,39 \\
\hline Rio G. Sul e S. Catarina & Escosteguy \& Bissani (1999) & 11,57 & 1,02 & 4,44 & 70 & $1,92^{*}$ \\
\hline Sul do Brasil & Kamiski et al. (2002) & 18,89 & 1,88 & 7,55 & 118 & $2,03^{*}$ \\
\hline Vale do Jequitinhonha & Presente trabalho & 19,81 & 0,99 & 6,39 & 100 & \\
\hline
\end{tabular}

(1) As equações utilizadas para estimar os teores de $\mathrm{H}+\mathrm{Al}\left(\mathrm{cmol}_{c} \mathrm{dm}^{-3}\right)$ a partir do pH SMP foram: $\mathrm{MG}$ : $\mathrm{Ln}(\mathrm{H}+\mathrm{Al})=8,06-1,111$ pH SMP; SP: Ln $(\mathrm{H}+\mathrm{Al})=7,76-1,053$ pH SMP; Cerrados: Ln $(\mathrm{H}+\mathrm{Al})=7,719-1,068$ pH SMP; $\mathrm{MS}: \mathrm{Ln}(\mathrm{H}+\mathrm{Al})=8,086-1,062$ pH SMP; RJ: Ln $(\mathrm{H}+\mathrm{Al})=7,75-1,02$ pH SMP; Nordeste Paraense: $\mathrm{H}+\mathrm{Al}=1,3294(\mathrm{pH} \mathrm{SMP})^{2}-20,173$ pH SMP + 78,63; Noroeste do Paraná: $\mathrm{H}+\mathrm{Al}=20,1925-2,6484 \mathrm{pH}$ SMP; Amazonas $\left.(\mathrm{pH} \mathrm{CaCl})_{2}\right): \mathrm{H}+\mathrm{Al}=30,155-3,834 \mathrm{pH} \mathrm{SMP} ; \mathrm{PE}: \mathrm{H}+\mathrm{Al}=0,4837$ $(\mathrm{pH} \mathrm{SMP})^{2}-8,4855$ pH SMP + 38,448; Semi-árido do Nordeste: $\mathrm{H}+\mathrm{Al}=3,1521(\mathrm{pH} \mathrm{SMP})^{2}-45,161 \mathrm{pH}$ SMP + 162,53; Norte de Minas Gerais: $\mathrm{H}+\mathrm{Al}=0,00359+1556,5806 \mathrm{e}^{-\mathrm{pH} \text { SMP }}$; Amazonas (pH água): $\mathrm{H}+\mathrm{Al}=30,646-3,848 \mathrm{pH} \mathrm{SMP} ; \mathrm{PR}: \mathrm{Ln}(\mathrm{H}+\mathrm{Al})=$ 6,068-0,744 pH SMP; RS e SC: Ln $(\mathrm{H}+\mathrm{Al})=6,68-0,9004$ pH SMP; Sul do Brasil: Log $(\mathrm{H}+\mathrm{Al})=3,020-0,371$ pH SMP; Vale do Jequitinhonha: $\mathrm{Ln}(\mathrm{H}+\mathrm{Al})=8,21-1,111414 \mathrm{pH}$ SMP.

*: Significativo a $5 \%$. 
laboratorista do que a determinação no sobrenadante, com o cuidado de tocar ligeiramente o bulbo do eletrodo apenas na camada de terra sedimentada no fundo do frasco, conforme indicado por Quaggio \& Raij (2001).

A necessidade de obter, de forma regional, a relação da acidez potencial com o $\mathrm{pH}$ SMP deve-se à diversidade dos solos brasileiros e à facilidade e ao menor custo da determinação do $\mathrm{pH}$ SMP.

\section{CONCLUSÃO}

Os teores de $\mathrm{H}+\mathrm{Al}\left(\mathrm{cmol}_{\mathrm{c}} \mathrm{dm}^{-3}\right)$ dos solos da Região do Vale do Jequitinhonha do Estado de Minas Gerais podem ser estimados por meio da equação de regressão: $\mathrm{Ln}(\mathrm{H}+\mathrm{Al})=8,26-1,124312 \mathrm{pH} \operatorname{SMP}\left(\mathrm{R}^{2}=0,97\right)$, para o pH SMP medido na suspensão solo:solução associado à rotina de determinação do $\mathrm{pH}$ em água.

\section{LITERATURA CITADA}

ALVAREZ V., V.H. \& RIBEIRO, A.C. Calagem. In: RIBEIRO, A.C.; GUIMARÃES, P.T.G. \& ALVAREZ V., V.H. eds. Recomendações para o uso de corretivos e fertilizantes em Minas Gerais. $5^{a}$ Aproximação. Viçosa, MG, CFSEMG, 1999. p.43-60.

CAMPOS, H. Estatística experimental não paramétrica. Piracicaba, Escola Superior de Agricultura Luiz de Queiroz, 1983. 349p.

CIPRANDI, M.A.O. Avaliação da metodologia de determinação da acidez ativa e potencial em solos do Rio Grande do Sul. Porto Alegre, Universidade Federal do Rio Grande do Sul, 1993. 90p. (Tese de Mestrado)

CORREAA, J.B.; COSTA, P.C.; LOPES, A.S. \& CARVALHO, J.G. Avaliação de $\mathrm{H}+\mathrm{Al}$ pelo método SMP. In: CONGRESSO BRASILEIRO DE PESQUISAS CAFEEIRAS, 12., Caxambu, 1985. Anais. Rio de Janeiro, Instituto Brasileiro do Café, 1985. p.111-112.

EMPRESA BRASILEIRA DE PESQUISA AGROPECUÁRIA. - EMBRAPA Centro Nacional de Pesquisa de Solos Rio de Janeiro, RJ. Manual de métodos de análise do solo. Brasília, SPI, 1997. 212p

EMPRESA BRASILEIRA DE PESQUISA AGROPECUÁRIA. - EMBRAPA. Centro Nacional de Pesquisa de Solos Rio de Janeiro, Sistema brasileiro de classificação de solos. Brasília, SPI, 1999. 412p.

ESCOSTEGUY, P.A. \& BISSANI, C.A. Estimativa de $\mathrm{H}+\mathrm{Al}$ pelo pH SMP em solos do estado do Rio Grande de Sul e de Santa Catarina. R. Bras. Ci. Solo, 23:175-179, 1999.

GAMA, M.A.P.; PROCHNOW, L.I. \& GAMA, J.R.N.F. Estimativa da acidez potencial pelo método SMP em solos ocorrentes no nordeste paraense. R. Bras. Ci. Solo, 26:1107-1113, 2002.

KAMINSKI, J.; GATIBONI, L.C.; RHEINHEIMER, D.S.; MARTINS, J.R.; SANTOS, E.J.S. \& TITSSOT, C.A. Estimativa da acidez potencial em solos e sua implicação no cálculo da necessidade de calagem. R. Bras. Ci. Solo, 26:1107-1113, 2002.
MAEDA, S.; KURIHRA, C.H.; HERNANI, L.C.; FABRICIO, A.C. \& SILVA, W.M. Estimativa da acidez potencial, pelo método do pH SMP, em solos do Mato Grosso do Sul. Dourados, Empresa Brasileira de Pesquisa Agropecuária, 1997. 25p. (Boletim de Pesquisa, 3)

MOREIRA, A.; ALMEIDA, M.P.; COSTA, D.G. \& SANTOS, L.S. Acidez potencial pelo método do pH SMP no Estado do Amazonas. Pesq. Agropec. Bras., 39:89-92, 2004.

NASCIMENTO, C.W.A. Acidez potencial estimada pelo pH SMP em solos do Estado de Pernambuco. R. Bras. Ci. Solo, 24:679-682, 2000.

PAVAN, M.A.; OLIVEIRA, E.L. \& MIYAZAWA, M. Determinação indireta da acidez extraível do solo $(\mathrm{H}+\mathrm{Al})$ por potenciometria com a solução tampão SMP. Arq. Biol. Tecnol., 39:307-312, 1996.

PEECH, M. Exchange acidity. In: BLACK, C.A., ed. Methods of soil analysis. Madison, American Society of Agronomy, 1965. p.905-913.

PEREIRA, M.G.; VALLADARES, G.S.; SOUZA, J.M.P.F.; PÉREZ, D.V. \& DOS ANJOS, L.H.C. Estimativa da acidez potencial pelo método do $\mathrm{pH}$ SMP em solos do Estado do Rio de Janeiro. R. Bras. Ci. Solo, 22:159-162, 1998.

QUAGGIO, J.A.; RAIJ, B. van \& MALAVOLTA, E. Alternative use of the SMP-buffer solution to determine lime requirement of soils. Comm. Soil Sci. Plant Anal., 16:245$260,1985$.

QUAGGIO, J.A. \& RAIJ, B. van. Determinação do $\mathrm{pH}$ em cloreto de cálcio e da acidez total. In: RAIJ, B. van; ANDRADE, J.C.; CANTARELLA, H. \& QUAGGIO, J.A., eds. Análise química para avaliação da fertilidade de solos tropicais. Campinas, Instituto Agronômico, 2001. p.181188.

RAIJ, B. van. Fertilidade do solo e adubação. Piracicaba, Ceres/ Potafos, 1991. 343p.

RAIJ, B. van; CANTARELLA, H. \& ZULLO, M.A.T. O método tampão SMP para determinação da necessidade de calagem de solos do Estado de São Paulo. Bragantia, 38:5769, 1979 .

RAIJ, B. van; QUAGGIO, J.A.; CANTARELLA, H.; FERREIRA, M.E.; LOPES, A.S. \& BATAGLIA, O.C. Análise química do solo para fins de fertilidade. Campinas, Fundação Cargill, 1987. 170p.

SAMBATTI, J.A.; SOUZA JUNIOR, I.G.; COSTA, A.C.S. \& TORMENA, C.A. Estimativa da acidez potencial pelo método do pH SMP em solos em formação caiuá Noroeste do Estado do Paraná. R. Bras. Ci. Solo, 27: $257-$ $264,2003$.

SHOEMAKER, H.E.; McLEAN, E.O. \& PRATT, P.F. Buffer methods for determining the lime requirement of soils with appreciable amounts of extractable aluminum. Soil Sci. Soc. Am. Proc., 25:274-277, 1961.

SILVA, C.A.; AVELLAR, M.L. \& BERNANDI, A.C.C. Estimativa da acidez potencial pelo $\mathrm{pH}$ SMP em solos do semi-árido do nordeste brasileiro. R. Bras. Ci. Solo, 24:689-692, 2000. 
SILVA, E.B.; DIAS, M.S.C.; GONZAGA, E.I.C. \& SANTOS, N.M. Estimativa da acidez potencial pelo $\mathrm{pH}$ SMP em solos da região norte do Estado de Minas Gerais. R. Bras. Ci. Solo, 26:561-565, 2002.

SILVA, F.C. Manual de análises químicas de solos, plantas e fertilizantes. Brasília, Empresa Brasileira de Pesquisa Agropecuária, 1999. 370p.
SOUSA, D.M.G.; MIRANDA, L.N.; LOBATO, E. \& CASTRO, L.H.R. Métodos para determinar as necessidades de calagem em solos dos cerrados. R. Bras. Ci. Solo, 13:193$198,1989$.

VETTORI, L. Métodos de análise de solo. Rio de Janeiro, Ministério da Agricultura, 1969. 24p. (Boletim Técnico, 7) 